\title{
TECHNICAL NOTE \\ A NOTE ON THE HUTT VALLEY STRONG-MOTION MICROZONE NETWORK
}

\section{R.G. Tyler* and R.T. Hefford*}

\begin{abstract}
A network of eight MO2 strong-motion accelerographs was established in the Hutt Valley between the years 1966-70 with a view to determining the effect of the local geology on earthquake attack on structures. The location of the instruments is shown in Fig. 1 and a typical cross-section of the Valley in Fig. 2. The instruments are all owned by the Physics and Engineering Laboratory (PEL), DSIR, apart from the one at the Haywards. Substation, which is owned by NZED but serviced by PEL.
\end{abstract}

So far some 27 records have been collected from the instruments for eight earthquakes which have occurred since 1966. No computer analyses have been carried out on the records. Peak accelerations are given in Table 1 .

A study of the results shows that, while the instruments on the alluvium generally show greater values of peak horizontal acceleration than those on the rock, more instruments would be needed to establish a pattern: in particular more down the centre of the valley.

Stephenson, in 1975, commenting (In the results obtained up to that time $(1)$. concluded that there was a "directed resonance" at sites on alluvium. For one such site, at PEL, "resonant motion for a range of earthquakes of different intensities and epicentres had nearly constant frequency and direction". He proposed that the resonance characteristics could be established in more detail by operating by radio links a network of mobile recorders to monitor the small earthquakes coming in at approximately once a week. The method could also be applied to other areas such as the Porirua Basin. So far such a scheme has not been implemented.

Because of the importance of the records already obtained from the instruments, vis a vis building design, it is proposed to examine them in detail, in particular those providing the peak acceleration values on 1.11 .68 and 18.1 .77 , with a view to computing response spectra.

\section{Reference:}

1. Stephenson W.R., "Cellular normal modes of alluvium response" Bulletin of the NZ Nat. Soc. Earthq. Eng. Vol. 8, No. 4, Dec. 1975 . 
TABLE 1: HUTT VALLEY MICROZONE NETWORK

Values of Peak Horizontal Acceleration for Recent Earthquakes (mm/ $\mathrm{sec}^{2}$ )

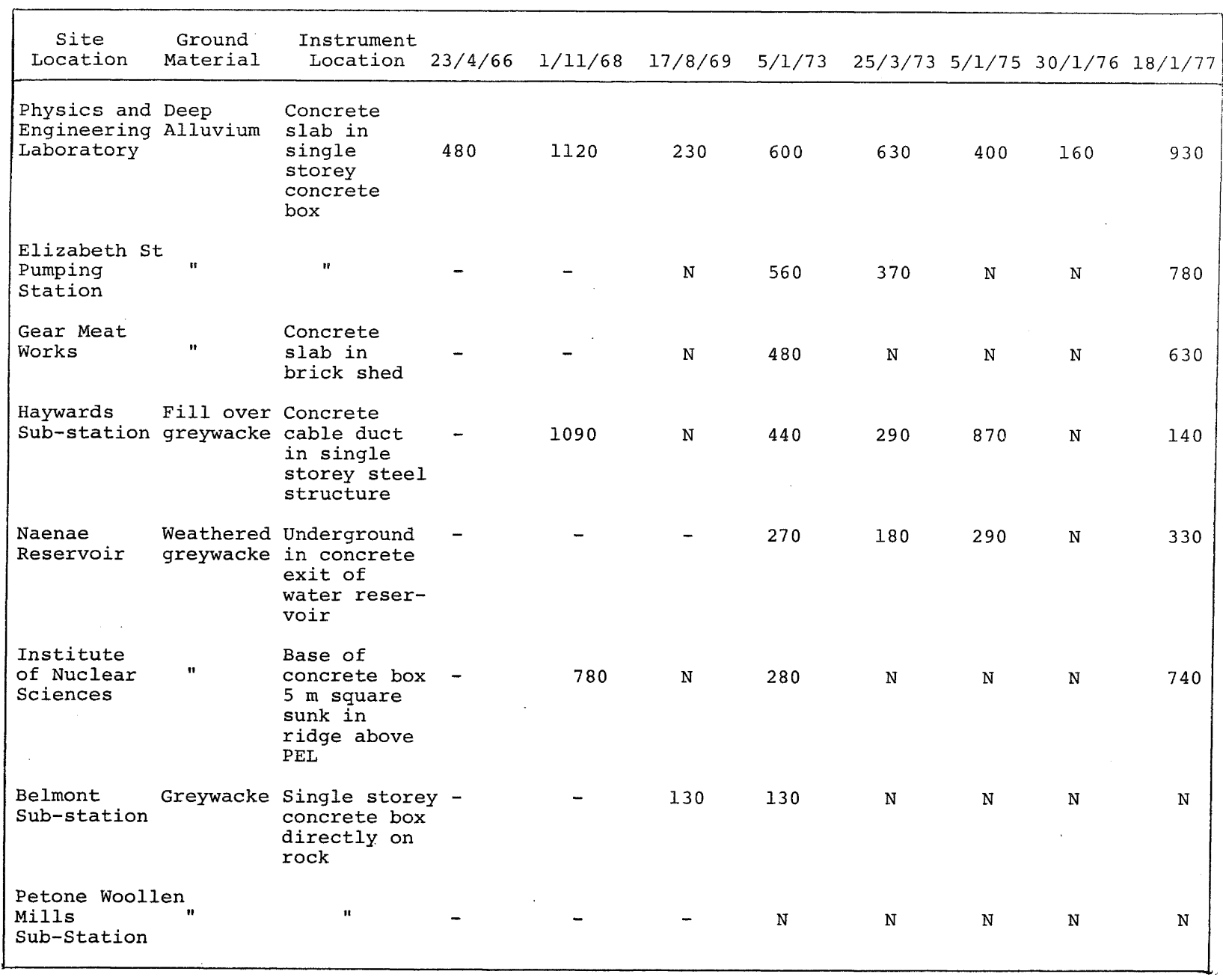

$\mathbf{N}=$ no triggering or late triggering giving negligible acceleration values.

FIg. 1 LOCATION OF STRONG MOTION

EARTHQUAKE RECORDERS

HUTT VALLEY MICROZONING

- instrument positions

$\triangle$ TRIG POINTS

NOTE:

SECTION D-D SHOWN ON Fig. 2

$\Delta 457 \mathrm{~m}$

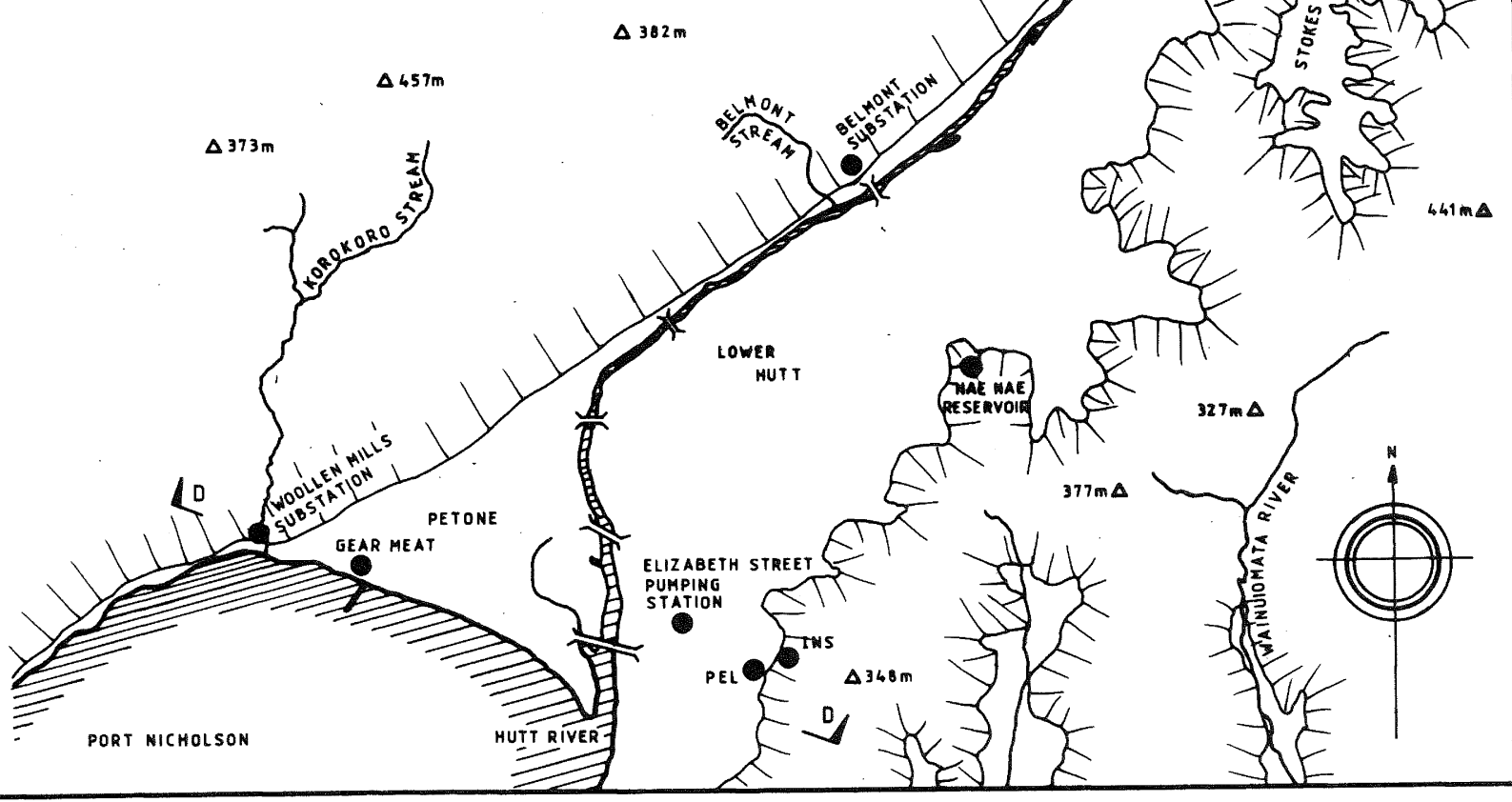




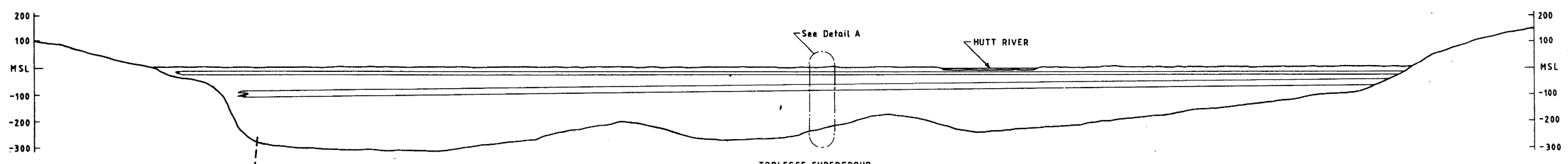

Wellington Foult

.

NOTE: SECTION D-D ORIIINATES FROM Fig.1

FROM INFORMATION SUPPLLED BY NZ GEOLOGICAL SURVEY

\section{SECTION D-D}

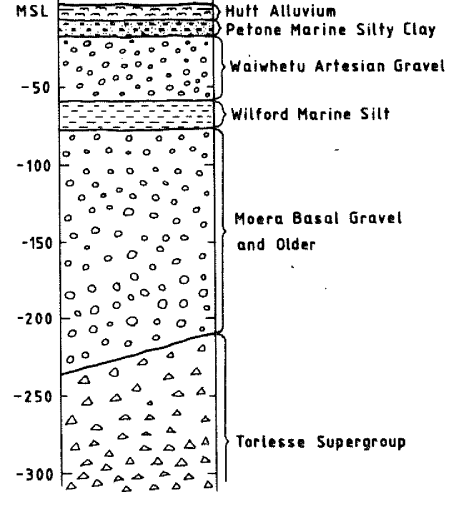

DETAIL A 